\title{
Chalmers Science School for International and Swedish Students
}

\author{
Sari Haj Hussein \\ Department of Computer Science \\ Chalmers University of Technology \\ Gothenburg, Sweden \\ Email: angyjoe@gmail.com
}

\begin{abstract}
This paper will describe the implementation of competitively based and highly structured scientific programs in a framework of a science school at Chalmers University of Technology. We discuss the implementation, advantages and disadvantages of those programs, the requirements students and supervisors should fulfill, whether from the academia or from the industry, and we present the selection method of participants. We also reflect on the results of a survey conducted recently among Chalmers academic staff. We believe that the installation of this science school at Chalmers brings many advantages to students, starting with a better understanding of industry practices and ending with an easier path to recruitment. It further helps employers in efficiently administering the process of hiring students and in discovering technological breakthroughs. Moreover, it enables the university to establish better connections with the industry and later use its feedback to enhance academic courses and the content of those courses. Our method derives from the successful practices of a pioneering science school at the Israeli Weizmann Institute of Science; namely the Kupcinet-Getz Science School for Israeli and International Students. The method further acquires practices from published literature of relevance to our discussion. We aspire Chalmers Science School to be a blueprint for any emerging or evolving science school at any educational institute worldwide.

Index Terms-science school, internship program, industrial training program, extended industrial training program
\end{abstract}

\section{INTRODUCTION}

The importance of combining theoretical classroom knowledge and practical experience is well recognized in all fields of science. The IEEE Computer Society "Model Program in Computer Science and Engineering" states that "Even though students can obtain an excellent education in a classroom environment, they must engage in meaningful exercises in designing and implementing hardware and software systems". Laboratory work is essential to create a balance between theoretical knowledge and practical experience. However, it is still considered an academic experience, so a more accurate balance is required. This later balance can be achieved through real-life hands-on experience in work scenarios that happen at industrial establishments, government facilities or even at educational institutes. Students can obtain such experience through summer jobs; however, a better choice is when universities themselves offer similar opportunities to students.

The trail blazers at the glorious Israeli Weizmann Institute of Science have understood students' needs to shape their future rather early in time when they launched the KupcinetGetz Science School in 1971 [1]. Since its establishment, this school has been receiving a large number of applications for each run and has always produced a world-class and wideranging scientific explorations. Today it is another tile that makes Weizmann stands head and shoulders above others; it is live case of the Israelis' addiction to thrive, advance and explore the unknown.

By transferring practices from Weizmann to Chalmers and relying on published literature and our own experimenting, we will suggest the installation of three types of scientific programs; Internship Program, Industrial Training Program and Extended Industrial Training Program.

The reminder of this paper is organized as follows: first, in Section III. we elaborate on the practices of the splendid Kupcinet-Getz Science School. Then, in Section III, we describe the implementation of the programs. Thereafter, in Section IV, we present the requirements of the programs. Subsequently, in Section $V$, we suggest some tasks that can be assigned to students taking the programs. Then, in Section VI. we give hints on how to publicize for the programs. Thereafter, in Section VII we describe the selection method of participants. Subsequently, in Section VIII and IX, we list the advantages and disadvantages of the programs respectively. Last but not least, in Section $\mathrm{X}$, we analyze and discuss the results of our survey.

\section{The KUPCINET-GETZ SCIENCE SCHOOL AT WEIZMANN Institute of SCIENCE}

The Weizmann Institute of Science [2], [3], [4] (Hebrew: Machon Weizmann LeMada) is a university and research institute in Rehovot, Israel. It differs from other Israeli universities (and most universities worldwide) in that it only offers MSc and $\mathrm{PhD}$ programs! The institute was founded in 1934 by Chaim Weizmann, formerly the president of the World Zionist Organization and later the first president of the State of Israel and the Weizmann Institute itself. The Weizmann Institute is one of the top-ranking research institutions in the world. It gathers together 2500 scientists, technicians and research students, all devoted to explore, better understand, see and penetrate the formerly incomprehensible to mankind. Through their greatest discoveries inside Weizmann, Amir Pnueli and Adi Shamir won the Turing Award; Ada Yonath won the Wolf Prize for Chemistry in 2006 and later the Nobel Prize for Chemistry in 2009. 
The Kupcinet-Getz Science School was established in 1971 in memory of Karyn Kupcinet. The name was later expanded in memory of Emma and Oscar Getz. The school is open to both international and Israeli students and is one of many summer schools active at Weizmann. The Feinberg Graduate School [5] administers this school. Every year, a selection of highly competitive students are invited to the school to engage in research projects in mathematics, physics, chemistry and computer science during the summer.

Student applicants are presented with a list of research projects currently active at Weizmann, of which they freely choose. Further, they are offered an opportunity to correspond with Weizmann's academic personnel to arrange for their supervision. An example research project from year 2010 is "Coping with NP-hardness" under Uriel Feige [6]. At the end of the summer program, students illustrate their findings in a short presentation and submit a written proposal. Proposals are later combined together in a book published by the institute.

The program is only open for undergraduate students, although it has been reported that Weizmann accepts postgraduate applicants to the Kupcinet-Getz School. The program lasts around 8 to 10 weeks. Each student receives a weekly allowance of 500 Israeli shekel. Application form can be filled and submitted online or offline and then post-mailed to Weizmann.

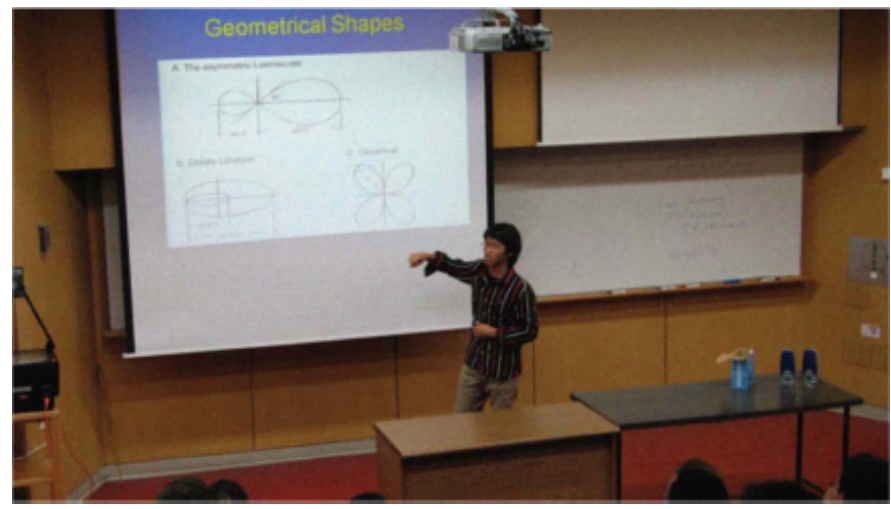

Fig. 1. International student presenting his work at Weizmann

\section{IMPLEMENTATION OF THE PROGRAMS}

\section{A. Implementation of the Internship Programs}

Three factors are needed to effectively implement the Internship Program [7]. First and foremost, motivated students should express interest in the program. Second, local industry should be willing to assign tasks, supervise and financially support students. Third, universities should encourage faculty to supervise students and should further take care of any monetary considerations that may arise from this.

The idea of an Internship Program originated in 1983 at the State University of New York in cooperation with the student chapters of IEEE and ACM at Binghamton. Then the program was unpaid and for high college credits only. Nevertheless and after completing a survey, sixty one percent of the students who had taken the program indicated that "credits only" program was quite palatable to them. Thus, an interested student is always there.

The next factor to satisfy is determining how interested local industry is. It is expected that most industries will be skeptical about the Internship Program particularly when answering the question "Can a student really do something for us over this relatively short period of time?". To push industry skepticism away, the Internship Program should be offered on a competitive basis to highly qualified students who are guaranteed to give a greater outcome in a shorter period. This strategy can further help in insuring that only the most enthusiastic students will participate in the Internship Program, not "whatever" students. Moreover such students will require the least amount of training and supervision; this reduces the load on (paid) industry employees.

The last factor to consider is universities support to the Internship Program in terms of encouraging faculty to supervise students and handling any monetary issues that may arise from this.

The Internship Program should be offered as a limited capacity course with few students participating each semester under supervision of just one faculty member per scientific discipline. This faculty member gets recognition as usual for working on the internship course. Adopting this strategy avoids overloading other faculty members. We should realize that a large proportion of faculties are already overwhelmed by their academic duties. One problem here is that the responsible faculty member can no longer teach one other course, but when the Internship Program succeeds and attracts international attention, the impact of this problem becomes negligible.

The monetary considerations universities should shoulder are few due to the fact that no extra costs need to be paid during the implementation of the Internship Program and later during supervision, in addition, no monetary compensation should be allocated for students.

\section{B. Implementation of the Industrial Training/Extended Indus- trial Training Program}

The Industrial Training/Extended Industrial Training Program differs from the Internship Program and is meant for large employers in Scandinavia who have an installed policy that no one can work unpaid for them. The Industrial Training/Extended Industrial Training Program is presumably longer than the Internship Program because most large employers believe that practicing their mass technological breakthroughs requires more time.

\section{INTERNSHIP/INDUSTRIAL TRAINING/EXTENDED INDUSTRIAL TRAINING PROGRAMS' REQUIREMENTS}

In all three programs, a student is asked to do much more than just routinely go to her job, therefore, a classroom should be installed for the programs in which students develop their communication skills through presentations and home assignments. The generic requirements of the programs can be summarized in the following [8], [9]: 
1) A student should work a minimum number of hours per week as suggested by her supervising faculty member. Non professional positions such as IT support or IT help desk are not permitted. The Internship, Industrial Training and Extended Industrial Training Programs differ only in the number of weekly hours of work and in whether a student receives payment or not.

2) A student should attend a seminar session (at least once per semester) where discussion on convenient positions is initiated by the supervising faculty member. Speakers from local industry should be invited and Chalmers Career Service Center should arrange for presentations on career-related topics. Part of the seminar session time should be allocated for the student to confer with seminar attendees about the company she is working for, her job description and her company's work environment e.g. equipment, buildings and employees' attitudes. Attending the seminar session(s) is mandatory for all students. Failure to do it should be reflected when grading.

3) A student should prepare and submit a "Learning Contract" in which she answers the questions; "What is the purpose of the job?", "What will she learn from it?" and "What methods will she use to accomplish her tasks?"

4) A student should prepare a recent curriculum vitae. Enclosed with it, she should attach a cover letter. Both of them to be used when applying to prospective positions offered through the programs. Chalmers Career Service Center should help the student in developing both documents and enlighten her about job searching techniques.

5) A student should keep track of her daily activities in a daily notebook where she describes tasks performed so far and dates and times those tasks were completed.

6) A student should submit a "Final Paper" by the end of her program summarizing her experience. The paper should include an overview of the job, the company and the working environment. In addition, the paper should tell whether or not the learning outcome specified in the Learning Contract was met or not, along with an explanation of failure at satisfying an item in the learning outcome. The purpose of excusing a failure is not to punish the student rather to help her to analyze herself. The paper should further assess the employer and its installed policies, describe the benefits for both the student and the employer and evaluate the seminar session(s) and the fruits gained from it. Together with the Final Paper, the student should include any documents and/or computer software developed over the course of the program. Any proprietary materials by the employer should be excluded.

7) The faculty member supervising a student should visit her (at least once per semester) at her workplace. In her meeting with the academic supervisor, the student should demonstrate her accomplishments and the responsibilities she is undertaking. The academic supervisor should double check with the employer to ensure that the student is performing well.
8) A student is evaluated by her employer and this evaluation is counted towards the final grade. The employer should consider the following indicators when evaluating a student; quality and quantity of student work, student competence and aptitude, student ability to learn and student communication skills.

Table I compares between the three programs with respect to number of work hours per week, duration in semesters and payment. Note that the numbers given in the table are our own estimations and can be changed when needed.

TABLE I

COMPARISON BETWEEN THE INTERNSHIP/INDUSTRIAL TRAINING/EXTENDED INDUSTRIAL TRAINING PROGRAMS

\begin{tabular}{llll}
\hline & $\begin{array}{l}\text { Internship } \\
\text { Program }\end{array}$ & $\begin{array}{l}\text { Industrial } \\
\text { Training Program }\end{array}$ & $\begin{array}{l}\text { Extended Industrial } \\
\text { Training Program }\end{array}$ \\
\hline $\begin{array}{l}\text { Number of work } \\
\text { hours per week }\end{array}$ & 10 & 20 & $20-40$ \\
$\begin{array}{l}\text { Duration in } \\
\text { semesters }\end{array}$ & 1 & 2 & 2 \\
Payment & No & $\begin{array}{l}\text { Yes } \\
\text { (amount varies) }\end{array}$ & $\begin{array}{l}\text { Yes } \\
\text { (amount varies) }\end{array}$ \\
\hline
\end{tabular}

All the aforementioned requirements are used when setting a student's final grade. Each requirement has a specific weight. Requirements and their weights are listed in Table III

TABLE II

WEIGHTS FOR SETTING A STUDENT'S FINAL GRADE

\begin{tabular}{ll}
\hline Requirement & Weight \\
\hline Learning Contract & $6 \%$ \\
Curriculum vitae and cover letter & $8 \%$ \\
Presentation & $10 \%$ \\
Final Paper & $19 \%$ \\
Daily log & $3 \%$ \\
Seminar attendance and participation & $4 \%$ \\
Employer evaluation & $50 \%$ \\
Total & $100 \%$ \\
\hline
\end{tabular}

\section{JOB DESCRIPTION}

One asks "What kind of job can a student do over a limited period of time?". Defining jobs to be performed by students is not a problem, and as the author is a computer science enthusiast, he compiled the following sample list of job descriptions:

1) Write an Assembly code to perform CPU timing.

2) Write a statistical package using SPSS.

3) Program a payroll system on a microcomputer.

4) Write an application program for energy consumption analysis.

5) Conduct training sessions to company staff on the use of some software packages.

6) Research the security of three different programming languages for the implementation of a web application.

The list can, of course, go on and on. 


\section{Publicizing the Programs}

An effective method for publicizing the programs is necessary. One such method is media in its varying forms, from printed documents to leaflets and newspapers, up to radio and TV. Another method is electronic announcements over the Internet through the university's website, newsletters and bulletin boards. Introductory sessions can be held at the university in appropriate times, normally before the start of a new program run.

\section{Participants Selection Method}

\section{A. Selecting Students to Participate in the Programs}

A student is asked to submit an application along with a curriculum vitae and (optionally) two letters of recommendation. A screening process of students' applications is conducted by the faculty and acted upon. Priority goes to senior students then to junior ones. If two candidate students have equal chance, other pieces of information in an application can be considered in the selection process. Interviewing candidate students is prohibitively expensive in terms of faculty time and geographic distribution of candidate students themselves. The solution is to get the companies to accept the candidates based on faculty members' recommendation.

\section{B. Selecting Companies to Participate in the Industrial Train- ing/Extended Industrial Training Program}

Student positions are not found by students rather by faculty members. As explained earlier, most companies will be skeptical about the programs. Therefore it is crucial that concerned faculty members (or their representatives) physically visit companies to present the programs (and some selling points) in order to persuade as many employers as possible to participate. During this, the faculty should emphasize the fact that only the very best students will be considered.

\section{ViII. Advantages of the Programs}

The advantages of the programs with respect to students are plenty [8], [9]. To start with, students enjoy high probability of obtaining permanent employment upon completion of the program. If they are not offered permanent employment, a certificate of experience from the employer is very worthwhile for them. Students learn as well to better present themselves and to better hunt for job opportunities, they gain insight into industry practices and realize the diversity of those practices, and enjoy improved communication skills, which are usually under-emphasized in university courses. In addition, students become more self-confident and aware of their abilities and in what capacity they can compete with their peers.

When we focus on employers, the programs bring many advantages. They help employers to assess the contents of university courses and programs, to evaluate top-quality students for future recruitment, and to face problems of hiring permanent employees to finish their small but desirable projects. The programs further help employers' current employees to develop their supervision and communication abilities, provide employers with fresh ideas and different view of how tasks can be completed, and give them a mean to invest more effectively because qualified students can become productive with a minimum amount of time and supervision. Moreover, the programs give employers the opportunity to investigate technologies that would have seemed intractable otherwise and let them enjoy an atmosphere of fun and humor students can create in the workplace.

When it comes to the university, we can harvest many fruits. The university, for example, develops better ties with local business and government bodies, enjoys recognition of its educational programs and respect for the quality of those programs, and enjoys a class of hardworking and motivated students because the strong competition between students wanting to take a program raises their awareness of the importance of a good academic record. We add that the university can directly obtain employers' requirements and can then consider those requirements in assessing current teaching norms and improving academic curricula, particularly when employer evaluations are used systematically over a number of years [10].

\section{Disadvantages of the Programs}

Any notion of any nature comes with both pros and cons and the suggested programs are no exception. Criticism of scientific programs is usually based on the following [8], [9]:

1) A student practices in only one work environment and if the environment is bad, the student learns bad practices. One of the requirements of the suggested programs is mandatory attendance of seminar sessions where each student talks about a job and hears about lots of other jobs. This helps in exposing bad work environments at the very beginning.

2) The quality of a student learning relies on the supervision provided by the employer. This can develop as a negative experience for the student. In the suggested programs, supervision is jointly provided by the employer and the faculty member. In case a student is not receiving a proper supervision in her current position, she is immediately withdrawn from it and transferred to another one.

3) The student may develop sarcasm towards her former education when she feels that the theories she learnt do not match the practices at the workplace. This should not be a problem if students are made aware beforehand that the functionalities of education and industry are not necessarily the same or if the students themselves start discovering industry needs at early stages of their education.

\section{Analysis of the Programs}

If the suggested programs become part of the educational process at Chalmers, then faculty members should prepare a survey by the end of each semester of a program run and send that survey to students and industrial supervisors. The feedback obtained from such survey can monumentally aid the university in improving the programs. Due to the fact that these programs are not yet implemented at Chalmers, analysis of students' and industrial supervisors' responses is impossible at this stage. 
In any event we have conducted a survey among Chalmers academic staff. The link to the survey was sent through electronic mail to staff involved in teaching and/or researching in various departments at Chalmers. Staff selection process was completely random. A dedicated collector was allocated for each department and those collectors were left open for a period of roughly one month - between March 24, 2010 and April 17, 2010. When aggregated, responses to survey questions were almost identical, and realizing that we got the largest number of responses from the Department of Technology, Management and Economic, we will cut down our analysis to that department only.

$60 \%$ of the responses we got came from $\mathrm{PhD}$ students, whereas $40 \%$ of them came from assistant, associate or full professors. This does not tell much except that $\mathrm{PhD}$ students are (likely) to give more time to experimenting and exploring new ideas than occupied professors can do, particularly when we understand the number of $\mathrm{PhD}$ students and professors in the randomly selected samples were almost equal.

$93.3 \%$ of our respondents think that a science school can benefit the research environment at Chalmers and that Chalmers can derive knowledge from other educational institutes while implementing such school. Unfortunately, few of our respondents indicated what those institutes are.

Tight connections with the university board are important to pass the faculty word in an influential manner. Unfortunately, only $13.3 \%$ of our respondents maintain such connections.

All our respondents believe that existing buildings at Chalmers can be used for the purpose of the school during the summer, and that the school should open the doors to students of all kinds, not only to European students.

The majority of our respondents believe that a summer intern can help with their research. Respondents who do not agree mainly attribute it to the fact that any summer course is time restricted therefore it would be hard for any student to digest all the input before she can come with an output.

Survey results revealed a slightly split decision about whether Chalmers should or should not recruit more staff to run the school during the summer. Yet another disagreement was seen among respondents when deciding on whether or not an extra summer payment is necessary.

Credits and a certificate of experience are agreed-upon rewards for a summer intern. A monthly allowance was suggested by very few respondents and we noticed that those respondents were mainly $\mathrm{PhD}$ students. Is it because there are summer schools for $\mathrm{PhD}$ students as well then they spontaneously projected themselves as students in Chalmers Science School?

\section{Conclusions}

In this paper, we suggested the installation of three scientific programs at Chalmers University of Technology. We stared by elucidating the implementation procedure for each program, then we elaborated on programs' requirements. Thereafter, we demonstrated the selection method of participants, and listed the advantages and disadvantages of the programs. We ended by reflecting on a survey conducted among Chalmers academic staff.

We believe that the scientific programs described in this paper can become a striking success in terms of providing students with hands-on experience, boosting university/industry connection and enhancing university curricula. We further surmise that these programs will receive strong acceptance in practice from students, employers and university staff alike.

\section{ACKNOWLEDGMENT}

I am deeply grateful for the proactive and valuable participation of Rebecca Bergman, Lene Nordrum and Leah Johannesson, from the Department of Applied Information Technology at Chalmers University of Technology, for making useful suggestions that improved this paper. As well, I would like to extend my gratitude to Lisbeth-Mariann Ekman for her perpetual support.

\section{REFERENCES}

[1] "The kupcinet-getz science school for international and israeli students," at: http://www.weizmann.ac.il/midrasha/summer/.

[2] "Weizmann institute of science," Wikipedia pages, at: http://en.wikipedia.org/wiki/Weizmann_Institute_of_Science.

[3] "Weizmann in brief," at: http://wiswander.weizmann.ac.il/site/EN/weizman.asp?pi=686\&doc_id=3821\&research=true.

[4] "Chaim weizmann," Wikipedia pages, at: http://en.wikipedia.org/wiki/Chaim_Weizmann.

[5] "The feinberg graduate school," at: http://www.fgs.org.il/en/.

[6] "Research interests of faculty members," Faculty of Mathematics and Computer Science, Weizmann Institute of Science, at: http://www.wisdom.weizmann.ac.il/math/research.shtml.

[7] J. Riehl, "Intensive internship: A model for improving entry-level systems productivity," in The Proceedings of the Twentieth Annual Computer Personnel on Research Conference, 1983, pp. 113-120.

[8] M. L. Schneider, N. S. Coulter, and J. C. Munson, "A successful student internship program," in Papers of the SIGCSE/CSA technical symposium on Computer science education, 1978, pp. 98-98.

[9] J. Buck and B. Shneiderman, "An internship in information systems: Combining computer science education with realistic problems," in Proceedings of the sixth SIGCSE technical symposium on Computer science education, 1976, pp. 80-83.

[10] N. J. Kubilus, "Assessing a computer science curriculum based on internship performance," J. Comput. Sci. Coll., vol. 15, no. 5, pp. 301307, 2000. 